\title{
The role of direct laryngoscopy in the diagnosis of laryngeal cleft
}

\author{
Paul D. Neubauer ${ }^{1}$, Laura H. Swibel Rosenthal ${ }^{2}$, William I. Wooten III ${ }^{3}$, Carlton J. Zdanski ${ }^{4}$, \\ Amelia F. Drake ${ }^{4}$ \\ ${ }^{1}$ Department of Surgery, Section of Otolaryngology, Yale-New Haven Hospital, New Haven, USA \\ ${ }^{2}$ Department of Otolaryngology_-Head and Neck Surgery, Loyola University Chicago, Stritch School of Medicine, Maywood, USA \\ ${ }^{3}$ Division of Pediatric Pulmonology, University of North Carolina Children's Hospital, Chapel Hill, USA \\ ${ }^{4}$ Department of Otolaryngology/Head and Neck Surgery, University of North Carolina Children's Hospital, Chapel Hill, USA \\ Email: paul.neubauer@yale.edu
}

Received 8 March 2013; revised 9 April 2013; accepted 17 April 2013

Copyright (C) 2013 Paul D. Neubauer et al. This is an open access article distributed under the Creative Commons Attribution License, which permits unrestricted use, distribution, and reproduction in any medium, provided the original work is properly cited.

\begin{abstract}
Objective: To identify the presenting features of a laryngeal cleft in children. To compare rigid and flexible endoscopic methods available for identifying laryngeal cleft and determine their utility. Methods: The charts of all patients diagnosed with laryngeal cleft in a tertiary care institution between 2009 and 2010 were evaluated retrospectively for age, gender, comorbidity, presenting features, and results of bedside swallow evaluation. Findings on flexible and direct laryngoscopy, both performed under general anesthesia, were compared. Results: Eleven patients had a diagnosis of laryngeal cleft, confirmed by direct laryngoscopy. Nine of eleven had signs of aspiration on modified barium swallow study (MBSS). Of the eight subjects who underwent flexible laryngoscopy by a pulmonologist, a deep interarytenoid groove was only reported in four cases. In all eleven cases, the arytenoids could be physically separated during direct laryngoscopy, allowing for definitive diagnosis of the cleft and identification of its type and severity. Conclusion: Video swallow studies and flexible laryngoscopy may raise suspicion or even diagnose a laryngeal cleft, however, a laryngeal cleft must be confirmed by direct laryngscopy in which the interarytenoid space is palpated. Furthermore, a patient in whom symptoms persist but no laryngeal cleft is identified on flexible examination should have a direct laryngoscopy to rule out a cleft.
\end{abstract}

Keywords: Laryngeal Cleft; Laryngoscopy; Aspiration; Children

\section{INTRODUCTION}

Laryngeal cleft is a rare congenital defect in the posterior larynx, possibly extending into the esophagus. An abnormal communication exists between the airway and the esophagus, leading to increased risk of aspiration.

Laryngeal clefts are described as one of four types. Type I is a deep interarytenoid groove that extends to the level of the vocal folds. Type II extends beyond the vocal folds to the cricoid cartilage. Type III extends past the cricoid cartilage to the cervical trachea. Type IV extends to the thoracic trachea [1]. Laryngeal clefts can be difficult to diagnose. The most common symptoms are reported to be stridor, cough, aspiration, and respiratory distress [2,3]. In general, a larger cleft will cause more severe symptoms [2]. A barium swallow study or esophagram may show aspiration. An examination of the larynx is necessary for diagnosis. However, a laryngeal cleft can go undiagnosed even on a flexible laryngoscopy or direct laryngoscopy, if the provider is not actively looking for it. The cleft may not be noticeable without an attempt to separate its edges. With direct laryngoscopy, the interarytenoid groove can be palpated and separated to diagnose laryngeal cleft.

Diagnosis of posterior laryngeal cleft is difficult using flexible bronchoscopy, which favors visualization of anterior structures and does not allow thorough probing of the interarytenoid area. There is no literature assessing flexible bronchoscopy for the diagnosis of laryngeal cleft.

\section{METHODS}

The charts of all children diagnosed with laryngeal cleft at North Carolina Children's Airway Center between 2009 and 2010 were evaluated retrospectively for age at diagnosis, age at first flexible bronchoscopy, age at modified barium swallow study (MBSS), gender, comorbidity, symptoms, and results of MBSS. Findings on flexible 
and direct laryngoscopy, generally performed simultaneously under general anesthesia, were compared. Duration between when patients had first flexible laryngoscopy and when they were diagnosed were calculated. Severity of symptoms and MBSS results were correlated to type of laryngeal cleft.

\section{RESULTS}

Eleven patients were included in the study (Table 1). There were 7 male and 4 female patients. The median age at diagnosis was 124 days with a range from 17 days - 17 months. The most common initial symptoms were choking (6/11), noisy breathing (5/11), stridor/wheezing (5/11), and cough (5/11). Most patients had GERD (6/11). Other initial problems included a history of respiratory infections (5/11), failure to thrive (1/11), and frequent otitis media (1/11). Seven of the eleven patients had congenital anomalies, which may have contributed to their presenting symptoms. Images from rigid endoscopy are shown for patients 2 (Figure 1), 3 (Figure 2), and 8 (Figures 3 and $\mathbf{4}$ ).

All patients had MBSS and direct laryngoscopy and eight of eleven patients had flexible endoscopy. On MBSS, nine of eleven patients aspirated. Two of the eleven patients aspirated thin consistencies only, one of the eleven aspirated semi-thick consistency only, and six of the eleven aspirated both thin and semi-thick consistencies. Two patients had no aspiration. All patients with a type II cleft aspirated both thin and semi-thick liquids. For one of these patients, patient 8, contrast was noted to extend from the airway to the esophagus "consistent with a direct communication”.

On flexible laryngoscopy, a deep interarytenoid groove was noted on four out of eight patients. Of the four patients who were noted to have a deep interarytenoid groove, two had a type I cleft and two had a type II cleft. Definitive diagnosis of laryngeal cleft was not made by flexible laryngoscopy in any patient. Other commonly diagnosed entities on flexible endoscopy were laryngomalacia (4/8), tracheomalacia (3/8), pharyngeal collapse $(3 / 8)$, and bronchomalacia (2/8).

Direct laryngoscopy confirmed the diagnosis of laryngomalacia in two out of four cases. Left vocal cord mobility could not be confirmed on one of the patients secondary to the level of sedation. On rigid bronchoscopy, weakness of the left vocal fold was also identified, although there were some fasciculations.

On direct laryngoscopy, all patients had palpation or separation of the interarytenoid groove. Seven patients had a type I laryngeal cleft, in which the cleft extended to the level of the true vocal folds. Four patients had a type II laryngeal cleft, in which the cleft extended beyond the level of the true vocal folds.

The average age at first flexible bronchoscopy was

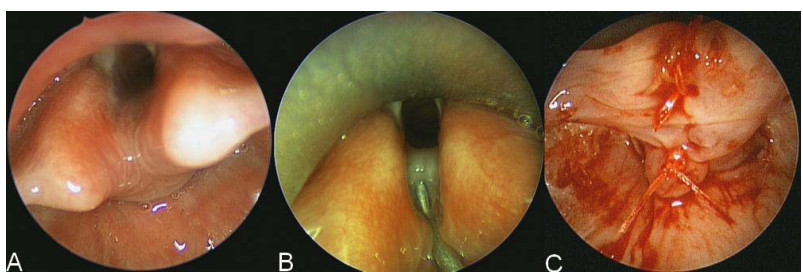

Figure 1. (A) Direct laryngoscopy of patient 2, with a type 1 cleft; (B) The cleft is appreciated only after palpation of the interarytenoid groove; (C) The cleft after endoscopic repair. Sutures are seen on the posterior interarytenoid mucosa.

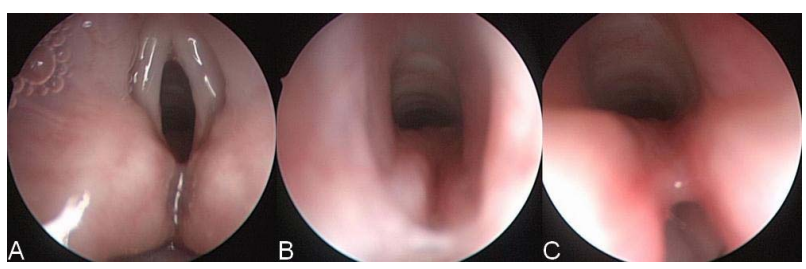

Figure 2. Images from direct laryngoscopy of patient 3 with a type II cleft show (A) the suspicious interarytenoid groove seen from above the level of the true cords; (B) the defect seen from below the true cords prior to separation with the bronchoscope; and $(\mathrm{C})$ the groove being separated with the bronchoscope. The cleft extends below the vocal folds. The esophagus or postcricoid space is seen posteriorly, and the airway is anterior.

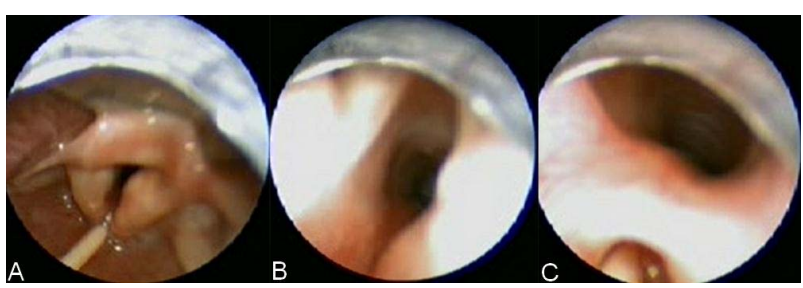

Figure 3. Images of type II laryngeal cleft from patient 8 show (A) the Dobhoff tube seen entering esophagus adjacent to cleft; (B) the true cords with the cleft extending below the level of the cords; and $(\mathrm{C})$ the inferior aspect of defect with trachea anteriorly and Dobhoff seen in esophagus posteriorly.

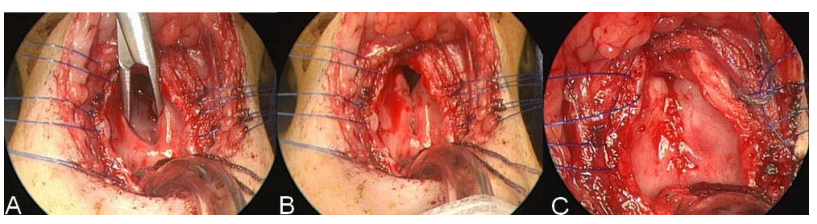

Figure 4. Images from a repair of laryngeal cleft of patient 8 show (A) a clamp in the esophagus through the laryngeal cleft, which extends about $2 \mathrm{~cm}$ below the level of the vocal folds. The laryngofissure is held open with the blue suture; (B) The natural position of the cleft without the clamp in place; (C) The repaired cleft with knots of the sutures buried towards the esophagus.

168 days. Four patients had their first flexible and rigid bronchoscopy on the same day and diagnosis was made at the same time. For patient 7, the diagnosis was made by rigid bronchoscopy one day after the flexible bronchoscopy, which had been suspicious for laryngeal cleft. 
Table 1. Patient characteristics.

\begin{tabular}{|c|c|c|c|c|c|c|c|c|}
\hline Patient & Comorbidities & Symptoms & Age at MBSS & $\begin{array}{c}\text { Findings of } \\
\text { MBSS }\end{array}$ & $\begin{array}{l}\text { Age at } \\
\text { first flexible } \\
\text { bronchoscopy }\end{array}$ & $\begin{array}{c}\text { Age at } \\
\text { first rigid } \\
\text { bronchoscopy }\end{array}$ & $\begin{array}{l}\text { Time from first } \\
\text { flexible } \\
\text { bronchoscopy } \\
\text { to diagnosis }\end{array}$ & $\begin{array}{l}\text { Cleft } \\
\text { type }\end{array}$ \\
\hline 1 & None & $\begin{array}{l}\text { Noisy breathing, } \\
\text { stridor, increased } \\
\text { respiratory effort } \\
\text { at night }\end{array}$ & $4 \mathrm{~m}$ & $\begin{array}{l}\text { Aspiration of thin } \\
\text { consistency }\end{array}$ & $4 \mathrm{~m}$ & $4 \mathrm{~m}$ & $\begin{array}{l}0 \mathrm{~m} \\
\text { (diagnosed at } \\
\text { time of first } \\
\text { bronchoscopy) }\end{array}$ & I \\
\hline 2 & $\begin{array}{l}\text { 22q11 deletion, } \\
\text { tetraology of fallot }\end{array}$ & $\begin{array}{l}\text { Noisy breathing, } \\
\text { cough, stridor }\end{array}$ & $4 \mathrm{~m}$ & $\begin{array}{l}\text { Aspiration of all } \\
\text { consistencies, } \\
\text { nasopharyngeal } \\
\text { reflux }\end{array}$ & $4 \mathrm{~m}$ & $4 \mathrm{~m}$ & $\begin{array}{l}0 \mathrm{~m} \\
\text { (diagnosed at } \\
\text { time of first } \\
\text { bronchoscopy) }\end{array}$ & I \\
\hline 3 & $\begin{array}{l}\text { Esophageal atresia } \\
\text { with TE fistula }\end{array}$ & Cough, choking & $\begin{array}{l}16 \mathrm{~m} \text { (cleft } \\
\text { previously } \\
\text { diagnosed but } \\
\text { unrepaired) }\end{array}$ & $\begin{array}{l}\text { Aspiration of thin } \\
\text { and semi-thick } \\
\text { consistency }\end{array}$ & 1 day & $4 \mathrm{~m}$ & $4 \mathrm{~m}$ & II \\
\hline 4 & $\begin{array}{l}\text { Developmental delay, } \\
\text { seizures }\end{array}$ & Cough, choking & $5 \mathrm{~m}$ & No aspiration & $9 \mathrm{~m}$ & $9 \mathrm{~m}$ & $\begin{array}{l}0 \mathrm{~m} \\
\text { (diagnosed at } \\
\text { time of first } \\
\text { bronchoscopy) }\end{array}$ & I \\
\hline 5 & $\begin{array}{l}\text { 8p microdeletion } \\
\text { involving a ubiquitin } \\
\text { gene (FBXO25) of } \\
\text { unknown clinical } \\
\text { significance, } \\
\text { developmental delay, } \\
\text { bifid uvula }\end{array}$ & $\begin{array}{l}\text { Noisy breathing, } \\
\text { cough, choking } \\
\text { with feeds }\end{array}$ & $5 \mathrm{~m}$ & $\begin{array}{l}\text { Aspiration of } \\
\text { semi-thick } \\
\text { consistency }\end{array}$ & $6 \mathrm{~m}$ & $6 \mathrm{~m}$ & $\begin{array}{l}0 \mathrm{~m} \\
\text { (diagnosed at } \\
\text { time of first } \\
\text { bronchoscopy) }\end{array}$ & I \\
\hline 7 & $\begin{array}{l}\text { Sotos syndrome, } \\
\text { seizures }\end{array}$ & $\begin{array}{l}\text { Noisy breathing, } \\
\text { stridor }\end{array}$ & $5 \mathrm{~m}$ & $\begin{array}{l}\text { Aspiration of thin } \\
\text { consistency }\end{array}$ & $15 \mathrm{~m}$ & $15 \mathrm{~m}$ & $\begin{array}{c}0 \mathrm{~m} \\
\text { (diagnosed at } \\
\text { time of first } \\
\text { bronchoscopy) }\end{array}$ & I \\
\hline 8 & $\begin{array}{l}\text { Transient tachypnea } \\
\text { of newborn, indirect } \\
\text { hyperbilirubinemia }\end{array}$ & $\begin{array}{l}\text { Choking, sputtering, } \\
\text { poor feeding, } \\
\text { lethargy }\end{array}$ & $24 \mathrm{~d}$ & $\begin{array}{c}\text { Contrast extending } \\
\text { from the esophagus } \\
\text { to airway consistent } \\
\text { with direct } \\
\text { communication }\end{array}$ & $\mathrm{n} / \mathrm{a}$ & 27 days & $\mathrm{n} / \mathrm{a}$ & II \\
\hline 9 & $\begin{array}{c}\text { Cleft lip/palate, } \\
\text { hypertelorism, } \\
\text { diahphragmatic hernia, } \\
\text { hypospadias, PFO, PDA }\end{array}$ & $\begin{array}{l}\text { Soft, hoarse } \\
\text { cry, feeding } \\
\text { difficulty }\end{array}$ & $18 \mathrm{~d}$ & $\begin{array}{l}\text { Aspiration of thin } \\
\text { and semi-thick } \\
\text { consistency }\end{array}$ & $\mathrm{n} / \mathrm{a}$ & 23 days & $\mathrm{n} / \mathrm{a}$ & II \\
\hline 10 & $\begin{array}{c}\text { Transient tachypnea of } \\
\text { newborn, PFO, PDA, } \\
\text { hypospadias }\end{array}$ & $\begin{array}{l}\text { Noisy breathing, } \\
\text { stridor, choking, } \\
\text { cough }\end{array}$ & $13 \mathrm{~d}$ & $\begin{array}{l}\text { Aspiration of thin } \\
\text { and semi-thick } \\
\text { consistency }\end{array}$ & $17 \mathrm{~d}$ & $17 \mathrm{~d}$ & $\begin{array}{c}0 \mathrm{~m} \\
\text { (diagnosed at } \\
\text { time of first } \\
\text { bronchoscopy) }\end{array}$ & II \\
\hline 11 & $\begin{array}{l}\text { Respiratory distress } \\
\text { syndrome, necrotizing } \\
\text { enterocolitis, osteopenia } \\
\text { of prematurity, } \\
\text { thrombocytopenia }\end{array}$ & Choking & $4 \mathrm{~m}$ & $\begin{array}{l}\text { Aspiration of thin } \\
\text { and semi-thick } \\
\text { consistency }\end{array}$ & $\mathrm{n} / \mathrm{a}$ & $4 \mathrm{~m}$ & $\mathrm{n} / \mathrm{a}$ & I \\
\hline
\end{tabular}


For patient 3, the diagnosis was made 128 days after first flexible bronchoscopy and for patient 6 it was made 351 days after first flexible bronchoscopy. Patients 8, 9, and 11 did not have a flexible bronchoscopy.

The rate of congenital anomalies seen in this study (7/11) is typical of laryngeal cleft patients. $56 \%$ of patients with laryngeal cleft are reported to have a congenital anomaly [4]. Additionally, there is a slight preponderance of males in this study (7/11), which is consistent with reported 1.2:1 - 1.8:1 male to female incidence [2].

\section{DISCUSSION}

Respiratory symptoms and feeding difficulties are common problems in children. Laryngeal cleft is an uncommon cause that can often be treated surgically. Perhaps owing to its rarity, there may be greater awareness of other problems besides laryngeal cleft which could cause similar symptoms, such as tracheo-esophageal fistula, laryngomalacia, vocal cord paresis, or GERD. Not all patients with respiratory and feeding difficulties will need a direct laryngoscopy, but increased awareness may help prevent this treatable problem from going undiagnosed. All patients undergoing direct laryngoscopy for evaluation of these symptoms should have palpation of the arytenoid area which is essential to definitively diagnose a laryngeal cleft. A rigid bronchoscopy with separation of the cleft may be necessary for further evaluation. Based on the referral patterns of the institution where this study was performed, it is not uncommon for patients to undergo evaluation by a pulmonologist for symptoms of chronic cough.

A direct laryngoscopy should be considered for patients whose symptoms are not improving or who are suspicious for having a laryngeal cleft even if a flexible bronchoscopy without any significant findings has been performed. Patients with prior direct or indirect laryngoscopy in which the interarytenoid space was not palpated, but in whom symptoms are still present despite treatment for other problems, should return to the operating room for direct laryngoscopy to complete evaluation for a laryngeal cleft.

Respiratory and feeding symptoms are often assessed by barium swallow study, which will usually show signs of aspiration if there is a laryngeal cleft. Patients may aspirate intermittently with laryngeal cleft, which could cause a cleft to be undetected with an MBSS [3]. Functional endoscopic evaluation of swallow (FEES) gives the examiner a better sense of the location of the aspiration, however, not all children can tolerate it [3]. Chien et al. suggest both MBSS and FEES be performed because they may provide distinct information. Even if there is no aspiration on swallow study, clinicians should still be suspicious of laryngeal cleft, as with patient 6 .

\section{CONCLUSION}

Respiratory and feeding difficulties, aspiration on video swallow and the appearance of a deep interarytenoid groove on flexible endoscopy may be able to raise suspicion and possibly even identify a rare laryngeal cleft in patients with otherwise common symptoms. However, a laryngeal cleft and its type must be confirmed by a direct laryngoscopy in which the interarytenoid space is palpated and the cleft can be clearly defined. This is especially important in type I clefts, in which signs and symptoms may be less severe and the cleft does not extend below the vocal folds. Rigid bronchoscopy may be necessary to diagnose type I clefts, but it is also important in evaluating the extent of longer clefts, the severity of which cannot be evaluated with laryngoscopy alone.

\section{REFERENCES}

[1] Watters, K. and Russell, J. (2003) Diagnosis and management of type 1 laryngeal cleft. International Journal of Pediatric Otorhinolaryngology, 67, 591-596. doi:10.1016/S0165-5876(03)00058-2

[2] Pezzettigotta, S.M., Leboulanger, N., Roger, G., Denoyelle, F. and Garabedian, E.N. (2008) Laryngeal Cleft. Otolaryngologic Clinics of North America, 41, 913-933. doi:10.1016/j.otc.2008.04.010

[3] Chien, W., Ashland, J., Haver, K., Hardy, S.C., Curran, P. and Hartnick, C.J. (2006) Type 1 laryngeal cleft: Establishing a functional diagnostic and management algorithm. International Journal of Pediatric Otorhinolaryngology, 70, 2073-2079. doi:10.1016/j.ijporl.2006.07.021

[4] Evans, K.L., Courteney-Harris, R., Bailey, C.M., Evans, J.N. and Parsons, D.S. (1995) Management of posterior laryngeal and laryngotracheoesophageal clefts. Archives of Otolaryngology-Head \& Neck Surgery, 121, 13801385. doi:10.1001/archotol.1995.01890120038007 